\title{
Degradation failure features of chromium-plated gun barrels with a laser-discrete-quenched substrate
}

\author{
Huaixue Li ${ }^{\text {a,b,* }}$, Guangnan Chen ${ }^{\text {a }}$, Kun Zhang ${ }^{\text {a }}$, Gengxing Luo ${ }^{\text {a }}$, Zhijun Ye ${ }^{\text {a }}$ \\ ${ }^{a}$ Institute of Mechanics, Chinese Academy of Sciences, Beijing, 100080, PR China \\ ${ }^{\mathrm{b}}$ Graduate School of the Chinese Academy of Sciences, Beijing, PR China
}

Received 30 November 2006; accepted in revised form 10 April 2007

Available online 19 April 2007

\begin{abstract}
The effect of substrate laser-discrete quenching on the degradation failure of chromium-plated gun barrels was metallurgically investigated. The results show that substrate laser-discrete quenching changes the failure patterns of chromium coatings during firing, and some periodic through-thickness cracks in the fired chromium coatings are justly located at original substrate zones between two adjacent laser-quenched tracks. Moreover, chromium coatings and the laser-quenched zones on the substrate are simultaneously degraded in microstructure and property during firing. Furthermore, the periodic structure of the laser-discrete-quenched steel (LDQS) substrate near the breech remains after firing, and the hardness of the fired laser-quenched zones is still higher than that of original substrates. The specific failure features were utilized to illustrate the mechanism of the extended service life of chromium-plated gun barrels with the LDQS substrate.
\end{abstract}

(C) 2007 Elsevier B.V. All rights reserved.

Keywords: Gun bore; Electrodeposited chromium; Interface; Laser-discrete quenching

\section{Introduction}

Chromium electrodeposits have been widely used as protective coatings for gun barrels due to their high hardness, excellent wear and corrosion resistance, high melting point and low manufacturing cost etc. [1-4]. It is well known that the surface of gun barrels is subjected to severe conditions, i.e. a short-term temperature and a high pressure pulse in the aggressive environment of the propellant gases during firing. The repeated cycling of high pressure and high temperature together with chemical interaction with hot propellant gases causes severe damage to chromium-plated gun barrels [4-16]. Moreover, the erosion damage of chromium-plated gun barrels is accelerated by chromium spallation, which allows hot gas attack and/or melting of the unprotected substrate steel [17]. With increasing demands for range, rate of fire, and muzzle velocity, increased wear and erosion problems in chromium-plated gun

\footnotetext{
* Corresponding author. Institute of Mechanics, Chinese Academy of Sciences, Beijing, 100080, PR China. Tel.:+86 1062547527 1; fax: +86 10 62561284.

E-mail address: 1hx1022@126.com (H. Li).
}

tubes have been caused, and the single traditional chromium plating cannot meet the practical requests. In order to improve the damage resistance of the substrate/Cr plating interface, various duplex surface techniques based on chromium plating, such as the combinations of chromium plating plus laser-surface hardening (or plasma nitriding), were proposed and investigated [18-22]. Recently, field firing indicates that the service life of a chromium-plated gun bore is greatly prolonged via the duplex process of substrate laser pre-quenching plus chromium postdepositing [22]. For revealing its mechanism, our previous work $[23,24]$ reported that laser quenching of the steel substrate can reduce the steep hardness gradient at the steel/chromium interface and improve the load-bearing capacity of chromium electroplate, and the microstructure and morphologies of the initial chromium layer copy the periodical surface gradient characteristics of the LDQS substrate.

To further reveal its mechanisms, it is very important to understand the effect of substrate laser-discrete quenching on the failure features of chromium-plated gun barrels. The focus of the present study is on the degradation failure features of chromium-plated gun bores near the breech with a LDQS substrate. It is found that some specific failure features are 

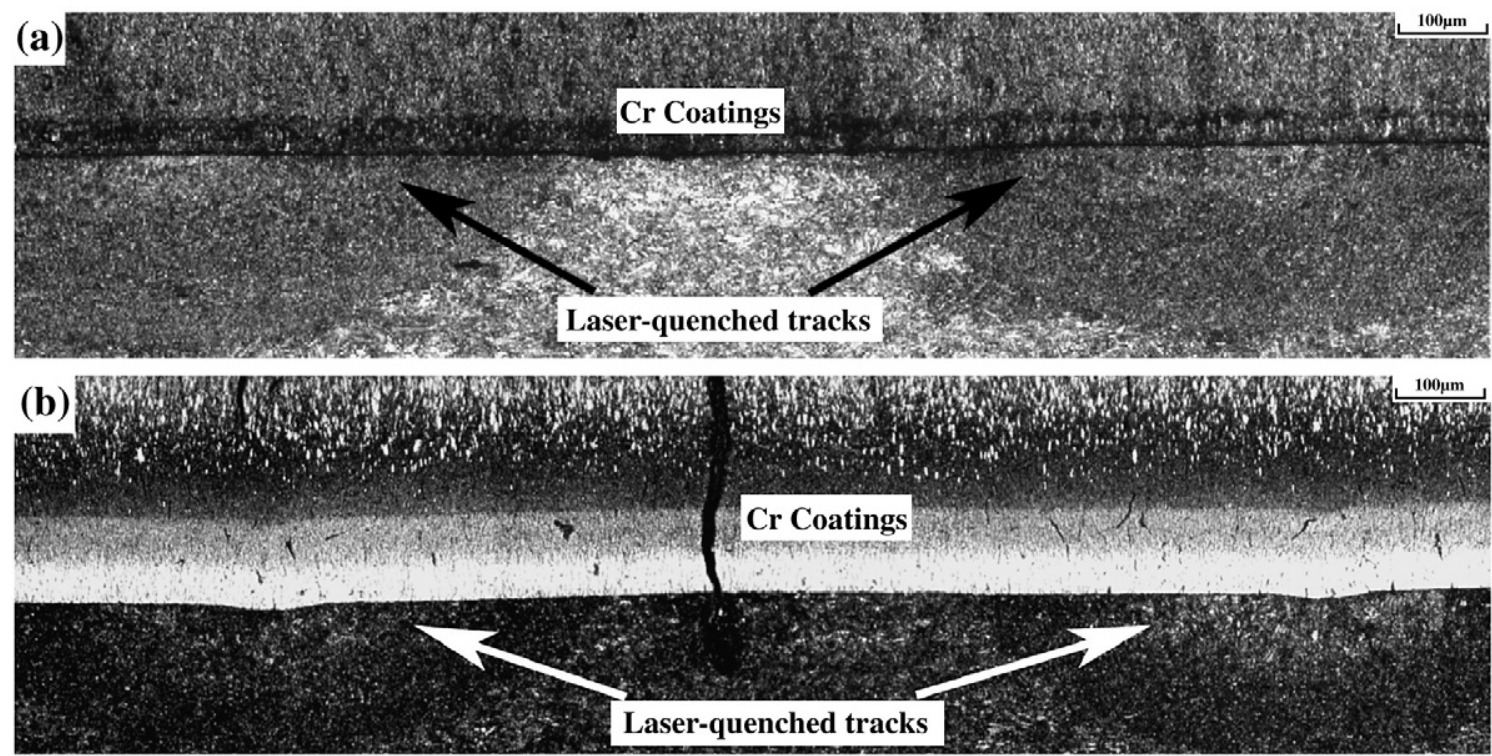

Fig. 1. Cross-sectional optical micrographs of a LDQS/Cr system; (a)-(b): before and after firing, respectively.

generated due to laser-discrete quenching prior to chromium plating. This permits illustrating the mechanism of the improved spallation-resistance of chromium plating.

\section{Experimental}

For the purpose of qualitative comparison, unfired reference specimens were cut from a chromium-deposited steel plate that was prepared via the simulated processes of the practice gun barrel. The steel plate was as-quenched and tempered AISI 3034 (main chemical ingredients: $0.28 \mathrm{C}, 0.7 \mathrm{Cr}, 2.27 \mathrm{Ni}, 0.20 \mathrm{Mo}$, $0.21 \mathrm{~V}$, all in wt.\%). The laser quenching and subsequent chromium electrodepositing of the steel plate were performed according to the preparation processes details in Ref. [23]. The chromium electrodeposits consist of underlying low-contraction (LC) chromium $\sim 20 \mu \mathrm{m}$ thick and top high-contraction (HC)
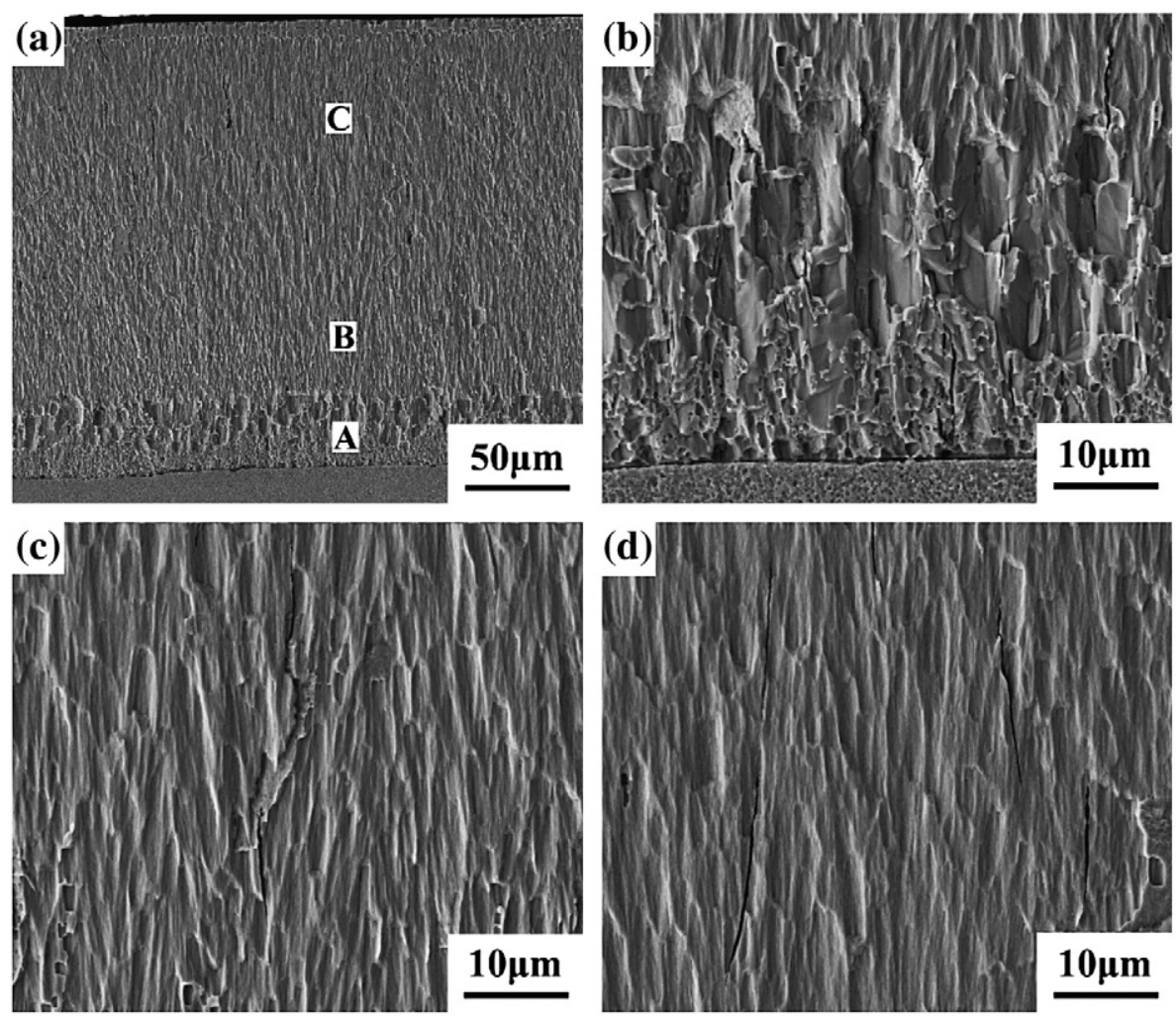

Fig. 2. SEM micrographs of the cross-section of chromium coatings before firing; (b)-(d): magnified images of Zones A-C in (a), respectively. 

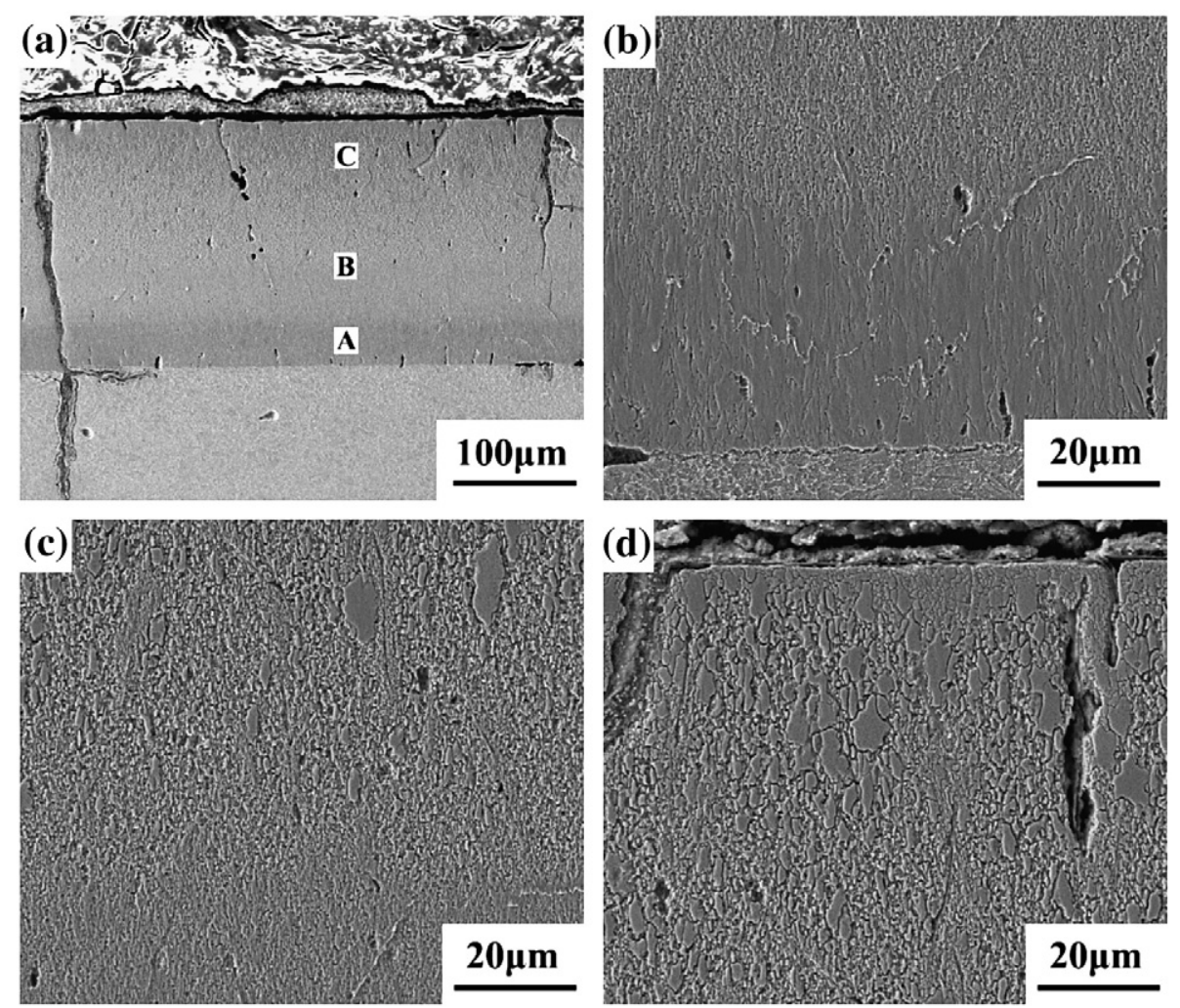

Fig. 3. SEM micrographs of the cross-section of chromium coatings after firing; (b)-(d): magnified images of Zones A-C in (a), respectively.

one $\sim 160 \mu \mathrm{m}$. Fired specimens were cut from an axial position at $\sim 28 \mathrm{~cm}$ from the beginning of the rifling of a machine gun tube after firing 3000 rounds. The gun barrel was laser prequenched with helix patterns prior to chromium plating. The specimens were prepared in the usual manner to permit the study of the degradation failure of the chromium plating and the laser-transformation hardened zones. Etching was carried out with $2 \%$ Nital to reveal laser-quenched zones. Dilute hydrochloric acid and modified Murakami's reagents were used as the etchants to study the unfired chromium deposits and fired ones, respectively. For several unfired and fired specimens, the chromium plate was dissolved away using dilute $\mathrm{HCl}$ alcohol solutions to permit examination of the cracking of the underlying steel substrate. Finally, all the samples were ultrasonically cleaned in alcohol. Morphological observations were carried out with optical microscope (OM) and high resolution scanning electron microscope (HRSEM) (FEI Sirion $400 \mathrm{NC}$ ) with EDS. The microhardness of the substrate and the chromium electrodeposits was measured by using a MH-6 Vicker's hardness tester with loads of $9.81 \mathrm{~N}$ (HV1).

\section{Results}

\subsection{Cross-sectional features of a $L D Q S$ substrate/Cr coating system}

Fig. 1 shows the optical micrographs of the cross-section of a LDQS substrate/Cr coating system before and after firing. As shown, the unfired chromium coatings are composed of two layers, namely top $\mathrm{HC}$ and underlying $\mathrm{LC} \mathrm{Cr}$; while there seems to be an obvious interlayer between $\mathrm{HC}$ layers and underlying LC ones in the fired chromium coatings. As illustrated in Fig. 1b, the damage of chromium coatings exhibits some common features as those previously established [4], that is, thermal shock cracking, recrystallization and grain growth in the top HC $\mathrm{Cr}$ layer. There are lots of large "white particles" in the fired HC $\mathrm{Cr}$ layer owing to recrystallization and growth of $\mathrm{Cr}$ grains, and the distribution of these particles shows gradient in the direction perpendicular to the surface. In addition, the laser-quenched

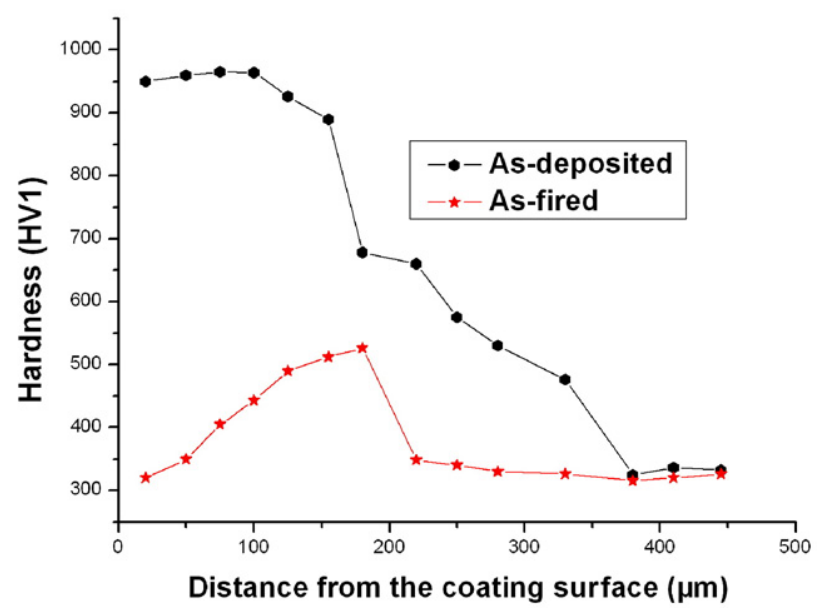

Fig. 4. Hardness profiles of a LDQS/Cr system at a laser-quenched zone center before and after firing. 

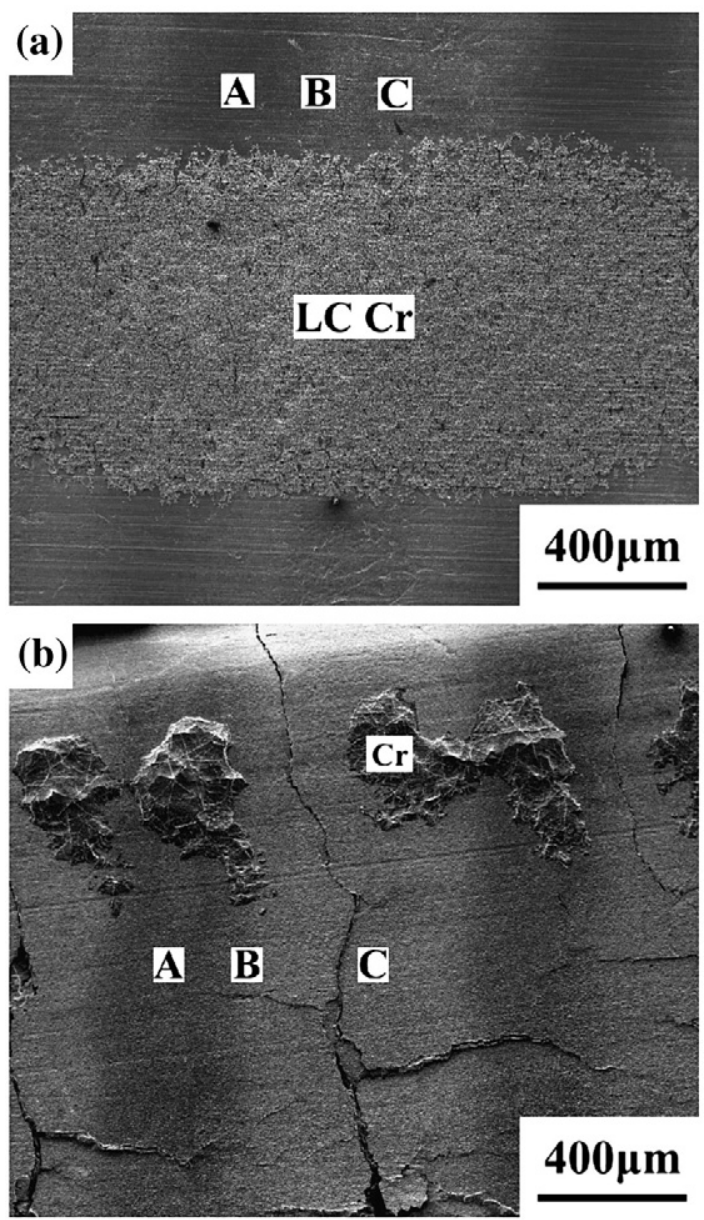

Fig. 5. SEM micrographs of unfired and fired LDQS/Cr interface planes after dissolving chromium coatings.

zones in crescent shape remain after firing, and their maximum depth is about $200 \mu \mathrm{m}$. It is interesting that some throughthickness cracks in the fired chromium coatings are justly located at original substrate zones between two adjacent laser tracks (see Fig. 1b). Moreover, it is seen that the LDQS/Cr system is a hierarchical composite structure.

Fig. 2 presents the SEM micrographs of the cross-sectional characteristics of chromium electrodeposits before firing. Closer views of the zones marked $\mathrm{A}-\mathrm{C}$ are shown in Fig. $2 \mathrm{~b}-\mathrm{d}$, respectively. As can be seen, The $\mathrm{HC} \mathrm{Cr}$ layer is composed of columnar grain clusters, and the columns are almost perpendicular to the substrate. There is no obvious structural difference between Zone B and Zone C in the $\mathrm{HC}$ Cr layer. As illustrated, the microstructure and morphologies of the LC layer are extremely different from those of the HC layer, and there are lots of block-like pits in the LC layer after etching in a hydrochloric acid etch. Compared to the LC layer, there are longer microcracks in the $\mathrm{HC}$ Cr layer.

Fig. 3 shows the cross-sectional features of the fired chromium coatings. Closer views of the zones marked $\mathrm{A}-\mathrm{C}$ are shown in Fig. 3b-d, respectively. It can be seen that there are some through-thickness and half-through cracks in the fired chromium coatings, and these cracks are filled with chemical reaction products. As illustrated, the new grain growth and resultant softening of chromium can be seen in Zone C compared to Zones A-B. Since the temperature fluctuation in the top $\mathrm{HC} \mathrm{Cr}$ layer is extremely different from that in the underlying LC one [25], the specific temperature distribution during firing results in gradient recrystallization and growth of chromium coatings, that is, non-synchronous degradation of the $\mathrm{HC}$ and LC chromium layers. Thus, the interlayer (marked B in Fig. 3a) between HC and LC Cr layers is obviously observed owing to non-synchronous degradations of Zones A-C.

\subsection{Hardness}

In order to understand the property degradation of chromium coatings and laser-quenched zones due to firing, hardness was measured from the coating surface to more than $400 \mu \mathrm{m}$ depth at a laser-quenched zone center before and after firing. The thickness of chromium coatings and laser-quenched zone is only $\sim 180 \mu \mathrm{m}$ and $\sim 200 \mu \mathrm{m}$, respectively. The measured hardness values at more than $400 \mu \mathrm{m}$ from the coating surface are the ones of the original substrate. The variations of hardness are presented in Fig. 4. As shown, the hardness of both chromium coatings and laser-transformation hardened zones decreases after firing, and hardness exhibits distinct gradient in the fired $\mathrm{HC} \mathrm{Cr}$ layer. The hardness value of the topmost $\mathrm{HC}$ chromium layers sharply falls from unfired $\sim 960 \mathrm{HV}$ to $\sim 320 \mathrm{HV}$ owing to severe recrystallization and growth of $\mathrm{Cr}$ grains. The hardness variation of chromium coatings is consistent with the microstructural features observed in Figs. 1-3. Although the hardness of the laser-quenched zones is drastically decreased after firing, it is still higher than that of the original substrate. This indicates that the substrate laser-quenching treatment can improve the load-bearing capacity of chromium electroplate and mitigate the property mismatch between original substrate and chromium coatings.

\subsection{Features of $L D Q S / C r$ interface planes}

Fig. 5 shows the surface morphologies of the unfired and fired LDQS/Cr interface planes after dissolving chromium coatings. The zones marked $\mathrm{A}-\mathrm{C}$ in Fig. 5 are the laser-transformation hardened zone, transition region and original substrate,

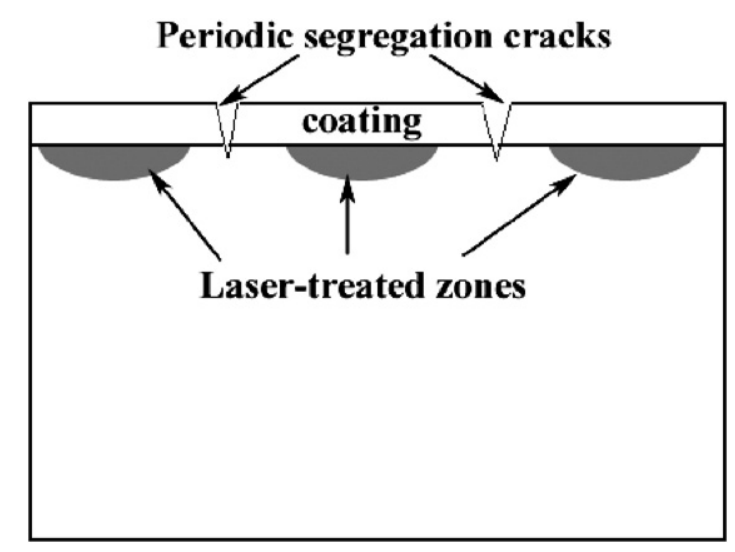

Fig. 6. Schematic of periodic cracks in the fired LDQS/Cr system. 

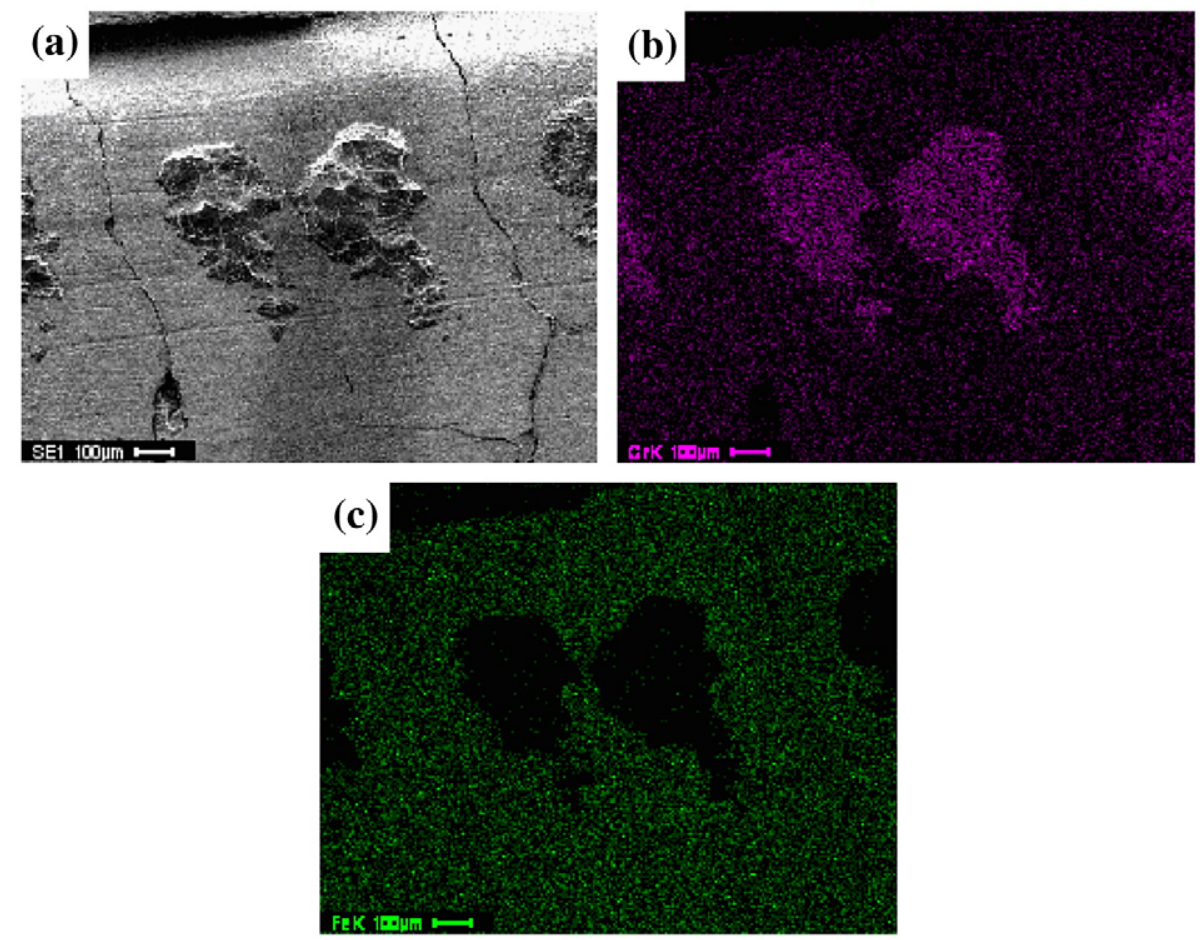

Fig. 7. Element distributions of the fired LQDS substrate with residual chromium layers.

respectively. It is seen that the microstructure and morphologies of the fired LDQS substrate exhibit the same periodic characteristics as those of the unfired one. Compared with the unfired substrate, however, there exist lots of cracks on the fired substrate surface. It is surprising that some periodical cracks are justly located at the original substrate spacing between two adjacent laser-quenched tracks, which implies that the periodical cracks penetrate through the fired chromium coatings into the substrate. According to Figs.
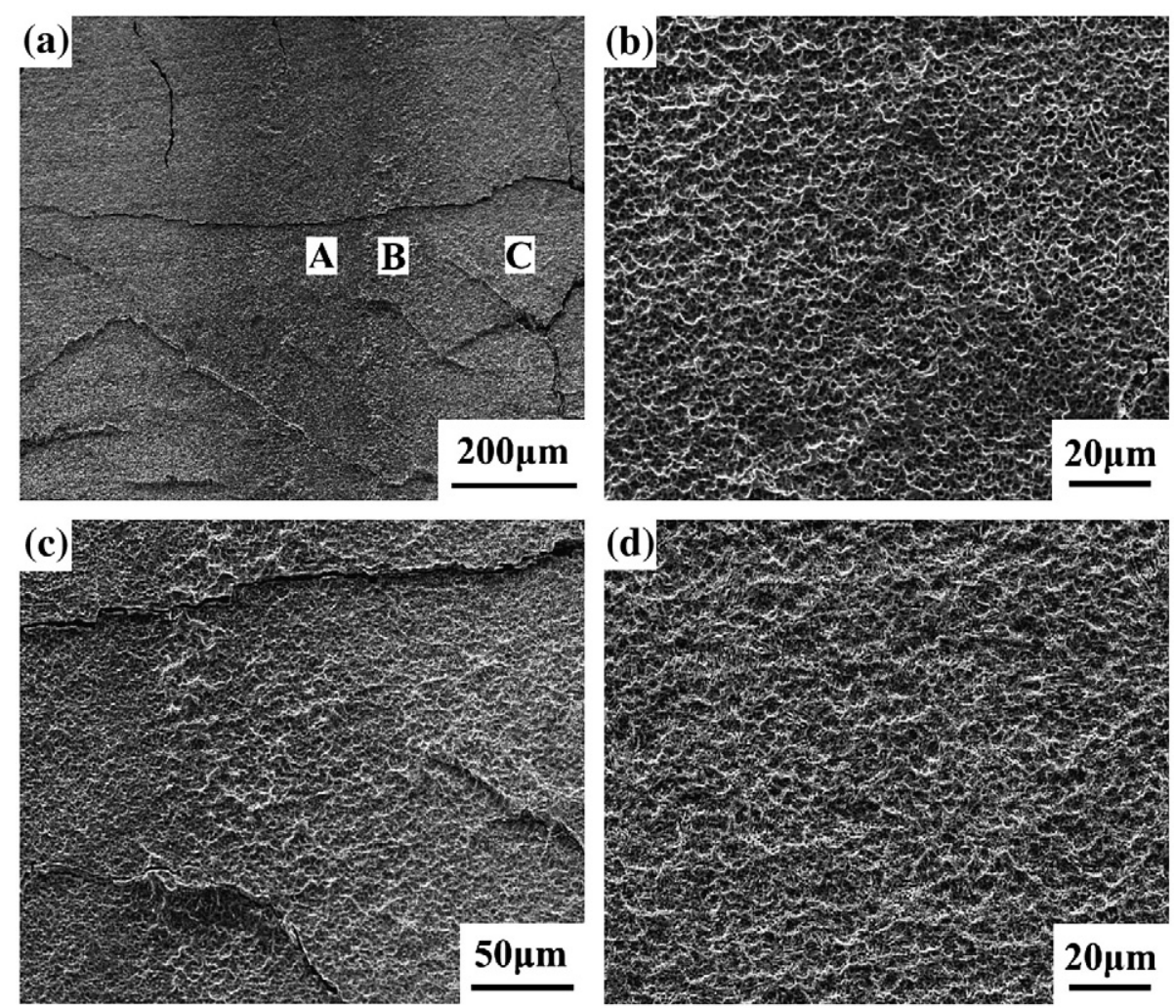

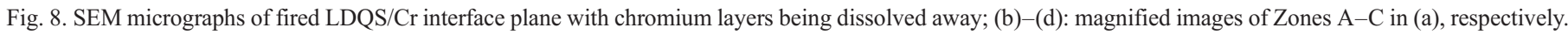


$1 \mathrm{~b}$ and $5 \mathrm{~b}$, the schematic geometry of the periodical throughthickness cracks in the fired LDQS/Cr system is drawn in Fig. 6. The special cracking pattern of the chromium coatings illustrates that the failure modes of the substrate/coating system are changed because of laser-discrete quenching of the steel substrate. Energy disperse spectrum (see Fig. 7) indicates that the element distributions of $\mathrm{Cr}$ and $\mathrm{Fe}$ on the fired LDQS substrate are well consistent with the surface morphology. It is further verified that there are residual block-like chromium layers on the fired substrate. In addition, there is only a residual LC chromium layer on the unfired substrate; while some block-like chromium layers remained on the fired substrate, and these chromium blocks are periodically distributed between two adjacent segmentation cracks. The extremely different topographies between the unfired $\mathrm{Cr}$ coatings and fired $\mathrm{Cr}$ ones are caused because of dissolution edge effects. As shown in Figs. 1b and 6, the fired chromium coatings are segmented into isolated islands through the periodic through-thickness cracks. When chromium coatings with isolated islands are dissolved, the edges of an individual isolated island are first removed away. Thus, the dissolution edge effects of isolated islands make some periodic chromium blocks retained on the fired LDQS substrate.

Fig. 8 shows the features of the fired LDQS/Cr interfacial planes where all of chromium coatings have been dissolved away. Closer views of Zones $\mathrm{A}-\mathrm{C}$ in Fig. 8a are shown in Fig. 8b-c. Zones $\mathrm{A}-\mathrm{C}$ represent the laser-transformation hardened zone, transition region and original substrate, respectively. As shown, the microstructure of Zone A is still finer and more even than that of Zones $\mathrm{B}$ and $\mathrm{C}$, and the morphologies of Zone B present gradient. Compared with Zone A, Zone C exhibits the alternative "plateau-valley" topography. Although the microstructures of Zone A are degraded owing to high temperature and mechanical stresses during firing, they are significantly different from those of Zones B-C. Owing to the microstructural heredity, the periodic gradient structure and topographies of the LDQS substrate have an important effect on the structure and damage resistance of the steel/Cr interface. It is well concluded that the degradation failure of a substrate/ coating system may be controlled via periodically modifying the meso-structure of the substrate surface.

\section{Discussion}

It is well known that there exist lots of embedded microcracks within the $\mathrm{HC} \mathrm{Cr}$ deposits. With exposure to high temperatures and mechanical wear from projectile passage during firing, the microcracks extend, and the surface microcracks, in particular, propagate through the chromium to the steel substrate, so that the original chromium plating becomes, in effect, an assembly of individual, isolated islands [17]. The chromium spalling process proceeds from this configuration by progressive removal of the individual isolated chromium islands through metal failure at or near the chromium-steel interface [17]. Therefore, one key measure to enhance the service life of chromium electrodeposits applied for gun barrels is to control segregation of chromium coatings and improve the damage resistance of individual isolated islands.
Since the barrel of the steel gun tube was discretely laser treated prior to chromium plating, the laser-treated zones with higher strength are periodically distributed on the gun barrel substrate. According to Fig. 2, the hardness of the laserquenched zones is always higher than that of the original substrate during firing. When chromium electrodeposits are subjected to the gas pressure and the projectiles' extrusion force, the original substrate zones between two adjacent laserquenched tracks first yield because of its lower yielding strength compared with the laser-treated zones. Cracks tend to initially introduce and propagate in the chromium layers on the original substrate. Owing to cycling thermal-mechanical stresses, these cracks are propagated through the chromium layers into the underlying substrate, and some periodical through-thickness cracks are generated in the fired chromium coatings (see in Figs. $1 \mathrm{~b}$ and 4 ). Thus, chromium coatings on the LDQS substrate are segmented into regular isolated islands (see Fig. 6).

The specific failure modes of the chromium coatings on the LDQS substrate have an important influence on the service life of a substrate/coating system. Wu et al. [26] reported that periodic segmentation cracking in the coating can decrease the macroscopic stiffness of the substrate/coating system, so that the coating can endure more strain mismatch. Moreover, Zhang et al. [27] reported that the isolated islands of chromium coatings applied for gun barrels with homogeneous substrates are random in size and distribution; and the average sizes of these isolated islands are much smaller than those on the LDQS substrate. According to Underwood's cyclic shear failure model of coating interface at an open interface crack [5], the interfacial cracks are easily formed at the edges of the isolated islands with exposure to cycling thermal/mechanical stresses due to edge effects. Since the microstructure and morphologies of both laser-quenched tracks and the initial as-deposited chromium layers on them are graded [23,24], the interface structure between an individual isolated island of $\mathrm{Cr}$ coatings and LDQS substrate is also graded. The functionally graded interfacial structures mitigate the thermal property mismatch between isolated islands and the substrate, and reduce the interfacial thermal shear stress. In addition, the larger size of the isolated islands can defer the connectivity of the edge interfacial cracks. It is well concluded that the spallation-resistance of chromium coatings on the LDQS substrate is significantly enhanced. Furthermore, since the degradation of chromium-plated barrel surface layers is graded due to its special operating conditions, the hierarchical structure of the LDQS substrate/chromium coating system is more suitable for the severe conditions during firing. Therefore, the service life of chromium barrels with the LDQS substrate is greatly enhanced.

\section{Conclusions}

Chromium coatings and the laser-quenched zones in gun barrels are simultaneously degraded in microstructure and property during firing. The periodic structure of the LDQS substrate in gun barrels can improve the bearing capacity of chromium electroplate, mitigate the thermal property mismatch between the substrate and chromium coatings, and change 
failure patterns of chromium electrodeposits. Laser-discrete treatment of the substrate in gun bores can control segregation of chromium coatings and improve the damage resistance of individual isolated islands. Therefore, the functionally graded interfacial structures are responsible for the longer service lives of chromium-plated gun barrels with LDQS substrates.

\section{Acknowledgments}

The financial support provided by the National Natural Science Foundation of China (Grant No. 50471087 and 50531060) is greatly acknowledged.

\section{References}

[1] R.A.F. Hammond, Trans. Inst. Met. Finish. 34 (1957) 83.

[2] D.M. Turley, Wear 131 (1989) 135.

[3] S. Sopok, C. Rickard, S. Dunn, Wear 258 (2005) 659.

[4] J.H. Underwood, G.N. Vigilante, C.P. Mulligan, M.E. Todaro, J. Press. Vessel Technol. 128 (2006) 168.

[5] J.H. Underwood, A.P. Parker, G.N. Vigilante, P.J. Cote, J. Press. Vessel Technol. 125 (2003) 299.

[6] J.H. Underwood, A.P. Parker, P.J. Cote, S. Sopok, J. Press. Vessel Technol. 121 (1999) 116.

[7] S. Sopok, C. Rickard, S. Dunn, Wear 258 (2005) 671.

[8] Eric Petitpas, B. Campion, J. Press. Vessel Technol. 125 (2003) 293.

[9] J.H. Underwood, E. Troiano, J. Press. Vessel Technol. 125 (2003) 287.
[10] J.H. Underwood, M.D. Witherell, S. Sopok, J.C. McNeil, C.P. Mulligan, G.N. Vigilante, Wear 257 (2004) 992.

[11] D. Crayon, A.E. Fish, E. Hyland, R.W. Messler, Exp. Tech. 7-8 (2002) 24.

[12] J.K. Hirvonen, J. Derek Demaree, D.K. Marble, P. Conroy, C. Leveritt, J. Montgomery, A. Bujanda, Surf. Coat. Technol. 196 (2005) 167.

[13] P.J. Cote, G. Kendall, M.E. Todaro, Surf. Coat. Technol. 146-147 (2001) 65.

[14] P. Cote, S.L. Lee, M.E. Todaro, G. Kendall, J. Press. Vessel Technol. 125 (2003) 335.

[15] R.S. Montgomery, F.K. Sautter, Wear 60 (1980) 141.

[16] P.J. Cote, M.E. Todaro, G. Kendall, M. Witherell, Surf. Coat. Technol. $163-164$ (2003) 478.

[17] P.J. Cote, C. Rickard, Wear 241 (2000) 17.

[18] R.S. Montgomery, Wear 155-166 (1979) 56.

[19] L. Wang, D.S. Kim, K.S. Nam, M. Kim, S.C. Kwon, Surf. Coat. Technol. 151-154 (2005) 190

[20] E. Menthe, K.-T. Rie, Surf. Coat. Technol. 217-220 (1999) 112.

[21] W. Harald, S. Uvc, Germany. Patent: DE19918794.

[22] G.N. Chen, G.X. Luo, K. Zhang, X.Y. Xu, H. Shen, H.M. Yan, D. Rao, Acta Armament II Suppl. 24 (2003) 6 (in Chinese).

[23] H.X. Li, G.N. Chen, G.X. Zhang, K. Zhang, G.X. Luo, Surf. Coat. Technol. 201 (2006) 902.

[24] H.X. Li, K. Zhang, G.N. Chen, G.X. Luo, Z.J. Ye, Surf. Coat. Technol. 201 (2006) 3709.

[25] B. Lawton, Wear 251 (2001) 827.

[26] C.W. Wu, G.N. Chen, K. Zhang, G.X. Luo, N.G. Liang, Surf. Coat. Technol. 201 (2006) 287.

[27] G.X. Zhang, G.N. Chen, K. Zhang, G.X. Luo, H.X. Li, Acta Armament II 27 (2006) 978 (in Chinese). 